\title{
UMA IGREJA DISTANTE DE ROMA: \\ CIRCULAÇÃO INTERNACIONAL E GERAÇÕES DE MISSIONÁRIOS NO MARANHÃO
}

A Church far from Rome: international circulation and generations of missionaries in the state of Maranhão

Wheriston Silva Neris E ERNESTO SEIDL

http://dx.doi.org/10.1590/50103-21862015000100008

Wheriston Silva Neris é professor de Sociologia do Campus III da Universidade Federal do Maranhão (UFMA) (wheristoneris@yahoo.com.br). Ernesto Seidl é professor do Departamento de Sociologia e Ciência Política e do PPG em Sociologia Política da UFSC, e pesquisador do CNPq (eseidl@terra.com.br).

Artigo recebido em 30 de dezembro de 2014 e aprovado para publicação em 27 de março de 2015. 


\section{RESUMO}

0 artigo examina as mutações na dinâmica católica em um território missionário - o estado do Maranhão dentro de registros aparentemente díspares: o local e o internacional, o religioso e o político. Procura-se assim entender como as redefinições nas formas de exercício do ofício eclesial nesse componente afastado dos centros de decisão católicos se conectaram às reconfigurações das modalidades de circulação internacional de clérigos em situação de missão no exterior, a partir de meados do século passado. 0 trabalho focaliza as condições nas quais se deu a nova onda de imigração religiosa de missionários do norte para o sul no período e, em seguida, as modificações no arcabouço institucional e nas formas de atuação religiosa, com destaque para os efeitos de politização da religião experimentados por frações de clérigos.

PalaVras-CHAVE: Igreja católica, circulação internacional, missionários, Maranhão.

\section{Abstract}

This article examines the changings within a Catholic mission territory - the state of Maranhão - from seemingly disparate aspects: local and international, religious and political. Focused on the second half of the $X X^{\text {th }}$ century, it aims to understand how the redefinitions of the ecclesial practice in that faraway region were connected to the reconfiguration of the international movement of clerics working in missions abroad. The work focuses on the new North-South wave of religious immigration, as well as on the changes in the institutional framework and in the forms of being a priest, highlighting the effects of politicization that affected some fractions of the clerigymen.

KeYwORDs: Catholic Church, international circulation, missionaries, State of Maranhão.

\section{RÉSUMÉ}

L'article examine les mutations dans la dynamique catholique dans un territoire missionnaire - l'état du Maranhão - sur des registres apparemment incongrus: le local et l'international, le religieux et le politique. II cherche à comprendre comment les redéfinitions de l' exercice de la fonction ecclésiale dans ce composant éloigné des centres de décision se sont connectés à la reconfiguration des modalités de circulation internationale de clercs en mission à l'étranger depuis la moitié du XXème siècle. II focalise les conditions dans lesquelles la nouvelle vague d'immigrations religieuses Nord-Sud s'est déroulée, ainsi que les changements dans le cadre institutionnel et les formes de l'activité religieuse, en particulier les effets de la politisation de la religion vécus par certaines fractions du clergé.

Mots-CLÉs: Église catholiques, circulation internationale, missionaires, État du Maranhão. 
m uma de suas últimas publicações, Appartenir à une institution: catholiques en

France aujourd'hui, Jacques Lagroye refletia sobre as múltiplas maneiras de viver o pertencimento à Igreja Católica, de participar de suas atividades e de construí-la praticamente. Segundo ele, "quando trabalha sobre a Igreja, o pesquisador não pode, com efeito, deixar de se interrogar sobre a surpreendente pluralidade das razões e as maneiras diversas de se investir na instituição" (2009: 6). É que uma das características fundamentais de agrupamentos complexos, como a instituição eclesial, consistiria justamente na pluralidade dos seus componentes, no fato de que seus membros jamais estão em contato com a totalidade da instituição, mas sim, quase sempre, com as propriedades dos componentes aos quais se vinculam concretamente, sejam eles paróquias, dioceses, ordens, congregações, movimentos específicos, comunidades de base etc. Assim, muito embora os católicos sejam constantemente lembrados - por uma série de dispositivos e processos, como ritos, cerimônias, sacramentos, discursos de religiosos - de sua vinculação a uma realidade que transcenderia a diversidade dos modos individuais e coletivos de pertencimento, sua representação da instituição não deixa de ser fortemente marcada por uma vivência concreta.

Estas perspectivas remetem a pelo menos duas exigências metodológicas que estiveram no ponto de partida deste trabalho. Em primeiro lugar, a problemática da definição do nível de análise de uma instituição hierárquica e tão codificada quanto a Igreja. Para Lagroye, é tão pertinente chamar de "instituição" tudo aquilo que é objetivado em regras, papéis, savoir-faire, dispositivos, quanto o próprio nível de suas objetivações sociais (direção administrativa romana, igreja nacional, dioceses, equipes de movimento, paróquias, ordens religiosas ou congregações). Não haveria, portanto, uma hierarquia entre esses diferentes níveis, mas sim ângulos distintos a partir dos quais se poderia ter uma visão desse artefato simbólico que é a instituição eclesiástica. Reconhecido isto, entram em questão os efeitos de conhecimento resultantes da variação da escala de observação, o que, como apontou Revel (1998: 20) a respeito da micro-história italiana, "não significa apenas aumentar (ou diminuir) o tamanho do objeto no visor, significa modificar sua forma e sua trama". Tal percepção converge com a de Lagroye, que afirma: "como o geral só é acessivel na exploração das singularidades, a instituição em seu sentido mais amplo só é acessível por meio daquelas experiências concretas e diversificadas que seus membros têm" (2009: 46). Logo, muito embora o pesquisador não possa desprezar a questão da dupla filiação dos membros da Igreja, ou seja, o fato de que 
sua vinculação a um componente concreto não exclui a própria consciência do pertencimento a uma instituição universal, uma segunda exigência consiste em tentar compreender como se estabelecem as relações de interdependência dentro dessa unidade plural.

Neste artigo procuramos examinar as lógicas que permitem pensar as mutações na dinâmica religiosa em um território missionário no Brasil - o estado do Maranhão - dentro de registros aparentemente díspares: o local e o internacional, o religioso e o político. Objetivamente, trata-se de pensar como as redefinições nas formas de exercício do métier eclesial nesse componente distante de Roma e dos centros de decisão nacional do catolicismo se conectaram, a partir de meados do século passado, às reconfigurações das modalidades de circulação internacional de clérigos em situação de missão no exterior. 0 trabalho apresenta duas formas de contextualização desse processo consideradas pertinentes para pensar os efeitos da interpenetração de histórias que está em jogo: a) as condições nas quais se deu a nova onda de imigração religiosa de missionários das igrejas do norte em direção às do sul a partir de meados do século XX; b) algumas das características da configuração eclesiástica em pauta, com atenção às modificações no arcabouço institucional e na composição dos efetivos clericais em exercício. Por essa via, buscamos ainda evidenciar o lento processo de diversificação das famílias religiosas e a pluralização dos pertencimentos eclesiais sob os influxos da desnacionalização dos efetivos encarregados de administrar a vida religiosa regionalmente. $A$ fim de conectar essas duas histórias, passamos em seguida à caracterização de duas configurações institucionais e missionárias nas quais se deu o ingresso e o engajamento de sacerdotes Fidei Donum no Maranhão.

\section{NOVAS DINÂMICAS TRANSNACIONAIS E IMIGRAÇÃO RELIGIOSA NO PÓS-GUERRA}

E mbora a questão da circulação de ideias, recursos humanos, técnicos e financeiros dentro da estrutura transnacional do catolicismo não constitua propriamente uma novidade, o argumento acerca da importância da Igreja internacional e de suas redes para os processos de renovação institucional no Brasil (Mainwaring, 2004) merece atenção. Uma das dimensões fundamentais dessa influência foi sem dúvida o processo de reafirmação da autoridade do Vaticano sobre as igrejas nacionais, iniciado já no século XIX, que fez com que a Santa Sé passasse a exercer um papel cada vez mais decisivo no encorajamento ou na proibição de mudanças (De Roux, 2014; Serbin, 2008). Mas essa influência não seria possível sem que um novo grupo de bispos acentuadamente europeizados a reivindicasse intencionalmente e estivesse em posição de se investir da função de promotor de reformas, encarregando-se de defender as prerrogativas do 
Vaticano dentro e fora da Igreja brasileira (Neris, 2014a). No nível do clero, a promoção da vinda de congregações masculinas e femininas também contribuiu para a assimilação pelo catolicismo luso-brasileiro de práticas religiosas de países como Itália, França, Bélgica, Holanda e Alemanha, demarcando "o processo de europeização do catolicismo brasileiro" (Wernet, 1997: 116).

Como demonstrado por Mainwaring (2004: 31), as inovações ocorridas na Igreja brasileira "entre o final da década de 1950 e o término da década de 1970 teriam sido impensáveis fora do contexto dos papados mais progressistas na história recente da Igreja". E está claro que a circulação de recursos para a Igreja latino-americana e brasileira foi beneficiada pela criação de organizações do episcopado e de atuação pastoral que rapidamente modificaram o estado de isolamento de muitas circunscrições e movimentos religiosos (Beozzo, 2001). Trata-se aqui do processo de construção institucional e do surgimento de uma Igreja efetivamente nacional (Iffly, 2010; Oliveira, 2005).

Nessa dinâmica destaca-se, de início, a criação da Conferência Nacional dos Bispos do Brasil (CNBB) em 1952. Três anos depois, essa experiência de unificação se estendeu ao continente latino-americano com a criação da CELAM - Conferência Geral do Episcopado Latino-Americano. Além da CELAM, a Confederação Latino-Americana de Religiosos (CLAR) e a Comissão Pontifícia para a América Latina (CAL), fundadas no fim dos anos 1950 por Roma, também ofereceram respostas a problemas organizacionais da Igreja, como sobretudo a escassez do clero, e a questões políticas e socioeconômicas do Cone Sul (Mendez, 2008). Essas instituições favoreceram a coordenação de várias organizações de caráter latino-americano ou interamericano, estimulando ações comuns, intercâmbios de ideias e a criação de redes religiosas transnacionais (Chaouch, 2007). Também auxiliaram na mediação de ajuda de episcopados da Europa e da América do Norte e de organizações de cooperação internacional católicas. A maior aproximação do episcopado no nível internacional fomentou as condições de cooperação missionária, e a atração de religiosos estrangeiros passou a figurar entre as alternativas para enfrentar os problemas da gestão diocesana em territórios missionários.

\section{UMA CIVILIZAÇÃO DIOCESANA DISTANTE DE ROMA E DOS CENTROS DE DECISÃO NACIONAL}

D e uma perspectiva histórica mais ampla, com o fim da união entre Igreja e Estado, atributos que eram competência exclusiva do Imperador passaram às mãos do episcopado. Do ponto de vista organizacional, isso significava que a criação de novas dioceses, paróquias e seminários, e a distribuição dos cargos e carreiras passariam a depender da alta hierarquia eclesiástica. Tratava-se de um efetivo ganho de autonomia institucional na medida 
em que os princípios de recrutamento e seleção eclesial passaram a ser progressivamente determinados por condicionantes próprios ao universo católico (Seidl, 2003). Além disso, como mostrou Miceli (1988), entrava em curso a afirmação de um modelo de organização centrado tanto sobre o reforço das linhas hierárquicas de autoridade e de comando episcopal quanto sobre a estadualização do poder eclesiástico, o que implicou a adoção pela hierarquia de estratégias específicas segundo as diferentes configurações regionais, as condições de manutenção do pacto oligárquico e o lugar que este passaria a ocupar no sistema sociopolítico.

Paralelamente à criação de uma cultura organizacional própria, tem-se a partir de então um impressionante crescimento do número de circunscrições eclesiásticas ${ }^{1}$ e da estrutura de postos dentro da Igreja, visando a torná-la presente em todo o território nacional. "Nos dez anos que seguiram a proclamação da República, o Brasil foi dividido em duas províncias eclesiásticas e nelas se criaram 5 dioceses" (Alves, 1979: 34). Entre 1890 e 1930 foram inauguradas 56 dioceses, 18 prelazias, 3 prefeituras apostólicas e numerosos seminários (Serbin, 2008). Em um período de 50 anos, a macroestrutura administrativa da Igreja cresceu notavelmente: em 1947, a instituição dispunha de 17 arquidioceses, 65 dioceses, 25 prelazias, 2 prefeituras apostólicas e 3.038 paróquias, conforme a Estatística do Culto Romano (1950). Atualmente, segundo dados do Anuário Católico de 2012, existem 275 circunscrições eclesiásticas (CERIS, 2012).

Entretanto, essa expansão institucional não ocorreu de forma homogênea no país. Com a atenção da Igreja voltada em especial para as regiões meridionais mais prósperas, as circunscrições de maior peso tenderam a ser criadas nas regiões Sul e Sudeste, deixando as regiões do Norte e parte do Nordeste com estruturas menos dotadas de recursos técnicos, humanos e organizacionais. Esse movimento refletia o processo histórico de deslocamento territorial dos centros de decisão política, econômica e institucionais no Brasil iniciado já em meados do século XIX.

Com o avanço do trabalho missionário impulsionado por Pio XI (1922-1939), no Brasil as prelazias e Prefeituras Apostólicas foram implantadas majoritariamente nas regiões Norte, Nordeste e Centro-Oeste. Para se ter uma ideia dessa evolução, se até 1920 haviam sido criadas apenas 9 prelazias no Brasil, a partir da década de 1930 já eram 18 e chegaram a 44 unidades em 1978. Somente no final daquela década passou a haver uma retração, quando a maior parte dos territórios de missão foi elevada ao status de diocese, cada uma vinculada a um bispo. Importa ressaltar que até a década de 1970 esses componentes institucionais constituíam universos à parte na comunidade católica brasileira. Fracamente influenciados por movimentos como o Concílio Vaticano II (1962-1965) e a adoção de Planos Pastorais de Conjunto elaborados pela CNBB entre os anos de 1958 e 1963, esses territórios encontravam-se principalmente sob o controle de Ordens e Congregações estrangeiras. Como resume Prezia (2003), das 36 prelazias existentes em meados da década de 1960, apenas 2 possuíam ma- 
joritariamente clérigos brasileiros: Diamantino (MT), a cargo dos jesuítas, e Marabá (PA), sob a responsabilidade dos dominicanos. As restantes estavam distribuídas principalmente entre congregações europeias e norte-americanas.

Ainda conforme Prezia, mesmo que o interesse pela problemática missionária tenha emergido em meados do século XX, por exemplo, com a realização do Congresso Eucarístico Internacional (1955) e do $2^{\circ}$ Congresso Nacional dos Religiosos do Brasil (1956), cada prelazia continuou sendo uma ilha destituída de contatos regulares com as demais. A essa situação de dispersão se associava um estado de baixa integração dentro do episcopado nacional, muito marcado pela diversidade de origens, pertenças, e pela própria diversidade de situações missionárias, notadamente entre as prelazias de recente criação e as áreas do antigo catolicismo colonial (Beozzo: 2001). Embora já existissem organismos como a CNBB suscitando a integração do episcopado, até o período do Concílio a maior parte das assembleias era realizada apenas com cardeais e arcebispos, excluindo-se os bispos e, de modo particular, os titulares das prelazias, o que não propiciava a constituição de laços firmes entre o conjunto dos prelados do país. Essa avaliação é bastante pertinente para caracterizar a Província Eclesiástica do Maranhão que, às vésperas do Concílio, encontrava-se dividida em 8 unidades: 1 Arquidiocese (São Luís), 2 dioceses (Caxias e Viana) e 5 Prelazias (Grajaú, Pinheiro, Balsas, Carolina e Cândido Mendes).

\section{A EVOLUÇÃo dos EFETIVOS RELIGIOSOS NO MARANHÃo}

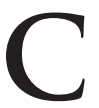

omo em todo o Brasil, o início do século XX correspondeu ao período de maior crescimento dos contingentes clericais vinculados a ordens e congregações estrangeiras, com modificações importantes na composição do corpo eclesiástico. Ainda que o Norte e o Nordeste não tenham sido focos de atração daqueles organismos no país (Serbin, 2008; Alves, 1979), mesmo em regiões periféricas como a Província Eclesiástica do Maranhão essa evolução dos efetivos religiosos dá a ver uma imagem da instituição progressivamente atravessada por linhas de divisão e concepção religiosas importadas e produtoras de relações diferenciadas em comparação com as condições tradicionais de exercício religioso. Tal quadro alterava significativamente a configuração eclesiástica vigente, de supremacia dos contingentes diocesanos (Serbin, 2008), paralelamente à crise e ao definhamento das ordens monásticas tradicionais em todo o Brasil (Wernet, 1997).

A ampliação da presença religiosa esteve relacionada, em primeiro lugar, ao apogeu da criação de novas congregações em nível internacional e à restauração das precedentes (Pelletier, 1996). "Entre 1880 e 1930, mais de três dúzias de ordens religiosas masculinas entraram no Brasil, e todas as ordens tradicionais do Brasil, menos uma, haviam sido restau- 
radas" (Serbin, 2008: 95). Principalmente de procedência europeia, foram diversas as famílias religiosas engajadas nessa onda imigratória: jesuítas, lazaristas, redentoristas, dominicanos franceses, capuchinhos franceses e italianos, salesianos italianos, carmelitas holandeses, beneditinos belgas e alemães, franciscanos alemães. 0 incremento foi ainda mais expressivo entre as ordens religiosas femininas. Em meados do século XX, o número de religiosas superava em muito a quantidade de padres, chegando a cifras expressivas de 40 mil (Serbin, 2008: 96).

Para o caso maranhense, dados das Estatísticas do Culto Católico Romano de 1943 davam conta da existência de 13 casas de congregações religiosas atuantes, 7 masculinas e 6 femininas, sem informar, no entanto, a quantidade de congregados. Como se vê nos quadros a seguir, a grande maioria das ordens e congregações nesse recorte provinha da Europa, com destaque para os religiosos italianos.

Quadro I: Ordens e congregações masculinas no Maranhão

\begin{tabular}{|clll}
\hline Qtd & Ordem & País de Origem & Entrada \\
\hline 1 & Capuchinhos & Itália & 1894 \\
\hline 2 & Lazaristas & França, Brasil & 1904 \\
\hline 3 & Irmãos Maristas & França & 1908 \\
\hline 4 & Lazaristas & Holandeses & 1937 \\
\hline 5 & Jesuítas & Itália & 1927 \\
\hline 6 & Missionários do Sagrado Coração de Jesus & Itália & 1946 \\
\hline 7 & Franciscanos da Província de Saxônia & Alemanha & 1952 \\
\hline 8 & Missionários Combonianos & Itália & 1952 \\
\hline
\end{tabular}

Fonte: Pacheco (1969).

Quadro II: Ordens e congregações femininas no Maranhão

\begin{tabular}{|llll}
\hline Qtd & Ordem & País de Origem & Entrada \\
\hline 1 & Filhas de Santana & Itália & 1886 \\
\hline 2 & Irmãs Doroteias & Itália & 1894 \\
\hline 3 & Irmãs dos Pobres de Santa Catarina de Sena & Itália & 1907 \\
4 & Irmãs Missionárias Capuchinhas & Itália & 1910 \\
\hline 5 & As filhas da Caridade de São Vicente de Paulo & França & 1938 \\
\hline 6 & Missionárias de Jesus Crucificado & Brasil & 1953 \\
\hline 7 & Irmãs Franciscanas da Imaculada Conceição & Austria & 1961 \\
\hline 8 & Filhas de Santa Teresa de Jesus & Brasil & 1962 \\
\hline 10 & Irmãs de Notre Dame de Namur & Bélgica & 1963 \\
\hline 11 & Irmãs Josefinas & Brasil & 1963 \\
\hline
\end{tabular}
Fonte: Idem. 
As formas de inserção social dessas ordens e congregações seguiram o que se poderia chamar de "ideário missionário moderno", que consistia grosso modo em combinar o tríptico "instruir, cuidar e construir" com os objetivos de apostolado religioso (Prudhomme, 2008: 50). A despeito de suas estratégias de discrição social, as congregações femininas foram responsáveis pela promoção de diversos projetos sociais como a criação de educandários, pensionatos, clubes de mães, orfanatos, atuando ainda em hospitais e nas colônias para leprosos em todo o Brasil (Bruneau, 1974; Serbin, 2008). O Instituto italiano das Irmãs Doroteias, por exemplo, chegou ao Brasil em 1866, e em 1894 no Maranhão, onde foi encarregado da administração, governo e direção do Recolhimento e do Asilo de Santa Tereza, local em que mais tarde foram instalados os cursos primário, ginasial, normal e colegial longo do século XX. Com a chegada das demais Casas, o investimento no campo da catequese e da educação ampliou-se muito. A Congregação das Irmãs Missionárias Capuchinhas - as mais numerosas no Maranhão no período - assumiu estabelecimentos de assistência a doentes, abriu diversos educandários femininos e forneceu aulas práticas de enfermagem, estando no princípio da criação da primeira Escola de Enfermagem do Maranhão. Especialmente em regiões do interior (Barra do Corda, em Codó, na cidade de Caxias) e nas prelazias de Balsas, Carolina e Grajaú, a atuação dessas missionárias se mostrou decisiva para o avanço da escolarização e a formação de profissionais de ensino (Pacheco, 1969).

Pelo lado masculino, a experiência missionária dos Capuchinhos Lombardos fornece campo de observação privilegiado para a compreensão da abrangência desse modelo de atuação missionária no Maranhão. Conforme vasto material produzido, a Missão Capuchinha do Norte do Brasil foi instalada oficialmente em 1893 e marcou o início da atuação sistemática da ordem na região. Sua chegada ao estado se deveu em grande medida a solicitações do Império e da Santa Sé para exercerem a catequese junto aos "silvícolas" do Amazonas (Betrami, 2001). Junto aos chamados "povos da floresta", os capuchinhos lombardos iniciaram a atuação com 13 religiosos, dos quais " 10 eram sacerdotes e 3 leigos e viviam em duas fraternidades do Maranhão e Barra do Corda" (Cuter, 1993: 20). Antes disso, porém, diversos capuchinhos já vinham se dedicando individualmente à ação missionária junto a povos indígenas na região (Meirelles, 1977). Além do trabalho apostólico realizado em numerosas paróquias do interior e nas santas missões, a atuação da ordem foi acompanhada por um forte engajamento educacional e sanitário. Em parceria com as Irmãs Capuchinhas, a abertura de colégios, hospitais e leprosários esteve também no centro da atuação pastoral da ordem e das estratégias de presença social missionária. Com a progressiva multiplicação de obras, a maior parte financiada por recursos vindos do exterior, esses religiosos foram capazes de produzir uma herança missionária que se constituiu em um bem não apenas admirado pela 
Igreja local, mas também em algo fundamental para a própria dinamização das comunidades em que atuavam (Neris, 2014b).

Ressalte-se que a afirmação desse modelo de atuação missionária não constituía exclusividade dos Frades Capuchinhos Lombardos. Como demonstrou o exame da atuação missionária dos Combonianos no Maranhão (Neris, 2014), o empreendimento missionário apresentava um caráter multidimensional capaz de suscitar impactos na vida política das comunidades e não somente no sentido político-partidário. Tais experiências podem ser pensadas assim como amplos programas de construção social com finalidades religiosas. Sobretudo em regiões onde a presença do poder público era mínima, como é o caso do espaço rural maranhense, por meio dessas iniciativas a Igreja foi se afirmando como uma espécie de instância supletiva de carências infraestruturais, com base em densa rede de instituições e iniciativas com forte capilaridade social. Ao mesmo tempo, mantinham-se os investimentos direcionados às elites, a exemplo do ocorrido em diversas regiões brasileiras (Dalabrida, 2001; Leonardi, 2002; Miceli, 1988; Seidl, 2003); porém, ao lado destes também se destacavam iniciativas voltadas para a população mais pobre e interiorana através da criação de escolas confessionais e de obras sociais diversas e combinadas aos objetivos de apostolado religioso (Schwartzman, 1986).

A principal consequência disso foi o reforço da influência global da religião em todos os aspectos da existência, no interior e na capital do estado, tanto entre as camadas sociais mais empobrecidas quanto entre os grupos dirigentes. Estamos aqui, portanto, diante de um modelo de atuação missionária perfeitamente combinável com as estratégias múltiplas de influência social que deram a tônica à gestão diocesana na primeira metade do século XX e colocaram à disposição da Igreja uma ampla rede de contatos. A despeito da dispersão geográfica das comunidades situadas no espaço regional, as atuações missionárias conseguiram assentar as bases de uma rede escolar e social que exerceu papel importante no avanço da escolarização e favoreceram os contatos, a integração e a circulação entre essas diferentes comunidades. 0 que fazia do religioso um mediador dentro da comunidade e entre esta e 0 exterior, gozando, ainda, de uma mobilidade que por vezes contrastava com o sedentarismo de parte dos padres seculares.

\section{REPRODUÇÃO DO CORPO CLERICAL DIOCESANO: CRISE CATÓLICA E DIVERSIFICAÇÃO}

exame da composição social do clero diocesano no início do século XX aponta a continuidade do vínculo entre recrutamento católico e universo rural, ${ }^{2}$ em especial os segmentos sociais menos providos de recursos econômicos e culturais. Paralelamente a 
uma diminuição do peso das "grandes famílias", assistiu-se a um incremento no número de "alunos brilhantes" vindos de pequenas comunidades de zonas rurais relativamente pobres do interior, ou mesmo de certas frações mais urbanas dos grupos dominados, cujo acesso à carreira eclesial significava possibilidade de ascensão. Entre 1945 e 1970, o declínio de vocações sacerdotais se aprofundou no Maranhão. Além do fraco número de candidatos ao sacerdócio, havia um aumento proporcional das vocações tardias e o envelhecimento dos efetivos nacionais em exercício. 0 incremento da segmentação das circunscrições eclesiásticas entre as décadas de 1950-1970 e o contínuo desenvolvimento de uma nova estrutura pastoral também contribuíram para complexificar a divisão do trabalho religioso regionalmente. Apesar da diminuição gradual da prática religiosa, a Igreja conservou sua capacidade de mobilização - como testemunha a crescente vinda de missionários estrangeiros (diocesanos, religiosos e leigos) na vida eclesial -, o que contribuiu para reconfigurar, não sem tensões, os modos de exercício clerical no seio desse componente periférico da Igreja Católica. É nesse contexto que se deve observar o impacto da convocação de missionários pertencentes a dioceses e institutos estrangeiros sobre os efetivos encarregados de cuidar da reprodução da Igreja no Maranhão.

A constituição progressiva de um universo religioso de maioria estrangeira e ligado a ordens e institutos é evidente. Já em 1952, dos 99 agentes atuando em paróquias em todo o estado, 58 eram regulares e 41 oriundos do clero diocesano. Ademais, se em 1950/1952 havia 16 instituições congregacionais no Maranhão, com 224 agentes (54 sacerdotes e 170 classificados como "outros"), em 1960 esse percentual havia saltado para 61 organizações, com um número total de 355 membros. Os últimos dados encontrados sobre a composição do clero remontam a 1965, quando havia 69 diferentes ordens e congregações atuantes naquele espaço, num total de 386 indivíduos. Os dados nacionais do CERIS também reforçam a evolução dos membros de institutos na região, principalmente no contingente de religiosas professas, como se pode ver no quadro IV.

Por outro lado, com a mencionada crise dos seminários, fonte central no recrutamento da Igreja, o clero diocesano se estagnou na região. Fechadas as portas do seminário em 1963, as dependências da instituição passaram a ser alugadas para a realização de eventos, congressos e simpósios, com o que a Cúria obtinha uma fonte de renda auxiliar (Meirelles, 1977). Nesse ínterim, os pretendentes ao sacerdócio eram deslocados principalmente para o Seminário de Fortaleza, único disponível para a Região Nordeste III (conforme classificação da CNBB), correspondente aos estados do Maranhão, Piauí e Ceará. Somente no final da década de 1970 o seminário foi reativado. ${ }^{3}$ A timidez da evolução dos efetivos presbiterais diocesanos é indicada no quadro $\mathrm{V}$. 
Quadro IV: Contingentes religiosos masculinos e femininos

\begin{tabular}{|c|c|c|c|c|}
\hline Regional & Ano & Masc. & Femin. & Total \\
\hline \multirow[t]{12}{*}{ NORDESTE 3 (MA, CE, PI) } & 1964 & 205 & - & 205 \\
\hline & 1965 & 252 & - & 252 \\
\hline & 1966 & 254 & - & 254 \\
\hline & 1967 & 270 & - & 270 \\
\hline & 1968 & 281 & - & 281 \\
\hline & 1969 & 284 & - & 284 \\
\hline & 1970 & 290 & 1.347 & 1.637 \\
\hline & 1971 & 284 & 1.371 & 1.655 \\
\hline & 1972 & 287 & 1.329 & 1.616 \\
\hline & 1973 & 281 & 1.374 & 1.655 \\
\hline & 1974 & 284 & 1.362 & 1.646 \\
\hline & 1975 & 279 & 1.371 & 1.650 \\
\hline \multirow[t]{14}{*}{ NORDESTE 4 (MA e PI) } & 1976 & & 1.360 & 1.360 \\
\hline & 1977 & & 1.344 & 1.344 \\
\hline & 1978 & & 1.358 & 1.358 \\
\hline & 1979 & & 1.361 & 1.361 \\
\hline & 1980 & 248 & 618 & 866 \\
\hline & 1981 & 251 & 629 & 880 \\
\hline & 1982 & 254 & 655 & 909 \\
\hline & 1983 & 268 & 687 & 955 \\
\hline & 1984 & 275 & 708 & 983 \\
\hline & 1985 & 279 & 759 & 1.038 \\
\hline & 1986 & 286 & 778 & 1.064 \\
\hline & 1987 & 293 & 807 & 1.100 \\
\hline & 1988 & & 862 & 862 \\
\hline & 1989 & & 907 & 907 \\
\hline \multirow[t]{11}{*}{ NORDESTE 5 (MA) } & 1990 & 144 & 572 & 716 \\
\hline & 1991 & 150 & 569 & 719 \\
\hline & 1992 & 148 & 592 & 740 \\
\hline & 1993 & 149 & 593 & 742 \\
\hline & 1994 & 156 & 626 & 782 \\
\hline & 1995 & 141 & 610 & 751 \\
\hline & 1996 & 142 & 615 & 757 \\
\hline & 1997 & 147 & 617 & 764 \\
\hline & 1998 & 140 & 615 & 755 \\
\hline & 1999 & 143 & 609 & 752 \\
\hline & 2000 & 151 & 594 & 745 \\
\hline
\end{tabular}

Fonte: Anuário Católico do Brasil (CERIS). 


\section{Quadro V: Sacerdotes diocesanos no Maranhão}

\begin{tabular}{|c|c|c|c|c|}
\hline Circunscrição Eclesiástica & 1963-1968 & 1970-1976 & 1980 & 1989 \\
\hline Arquidiocese de São Luís & $1965-51$ & $1976-17$ & 21 & 18 \\
\hline Grajaú & - & $1976-2$ & 18 & 6 \\
\hline Caxias & $1967-13$ & $1974-11$ & $\sim 11$ & 13 \\
\hline Pinheiro & $1966-20$ & $\begin{array}{l}1970-17 \\
1976-17\end{array}$ & 14 & 15 \\
\hline Balsas & - & - & 2 & 5 \\
\hline Carolina & - & - & 4 & 4 \\
\hline Candido Mendes/Ze Doca & $1968-6$ & $1976-6$ & 8 & 6 \\
\hline Viana & $\begin{array}{l}1965-7 \\
1968-9\end{array}$ & $1976-7$ & 3 & 10 \\
\hline Bacabal & - & $\begin{array}{l}1970-2 \\
1976-5\end{array}$ & 6 & 8 \\
\hline Brejo & - & $1971-20$ & 9 & 9 \\
\hline Coroatá & - & - & 10 & 14 \\
\hline Imperatriz & - & - & - & 6 \\
\hline Totais & Aprox. 99 & Aprox. 85 & Aprox. 106 & 114 \\
\hline
\end{tabular}

Se entre 1963 e 1968 o número de sacerdotes diocesanos (nacionais e estrangeiros) no Maranhão era de aproximadamente 99, esses efetivos foram reduzidos ainda mais entre 1970 e 1976. Todos os indícios apontam que as modificações mais importantes nos efetivos presbiteriais diocesanos durante os decênios de 1960-1980 estiveram associadas à chegada de sacerdotes vinculados a dioceses de fora do Brasil. A maior parte desses diocesanos estrangeiros chegou a partir da década de 1960, encorajados pela Encíclica Fidei Donum - publicada pelo Papa Pio XII em 1957 - a se engajar nas missões da África e da América Latina.

Essa importância numérica dos estrangeiros dentro do universo clerical local pode ser constatada, por outro lado, pelo conjunto de críticas veiculadas por missionários atuantes no estado do Maranhão, que evidenciavam a sobrecarga decorrente da penúria da produção de vocações regionais. Conforme matéria do Jornal do Maranhão (16/06/1968, n 3.752, p. 2), os padres missionários queixavam-se: "dados de 1965 revelam que a Igreja do Maranhão dispunha naquela época de 130 sacerdotes de ambos os cleros: 67 eram brasileiros e 63 estrangeiros. Hoje, em 1968, há no Maranhão 212 sacerdotes seculares e religiosos, sendo 58 brasileiros e 154 estrangeiros". Da mesma forma, no jornal O Estado de S. Paulo (18/08/1974, p. 28), o padre italiano Vitorio Luchesi, responsável por uma fraternidade de seminaristas em São Luís, além de lamentar o fato de que a "Igreja do Maranhão é uma das mais pobres do 
mundo quanto ao clero e às vocações sacerdotais", declarava que "o número total de padres do Maranhão é de 212 e desses apenas 51 são brasileiros. A Regional Católica do Nordeste, constituída de 3 estados - Maranhão, Piauí e Ceará - possui um único seminário maior localizado em Fortaleza".

\section{CONFIGURAÇÕES INSTITUCIONAIS E GERAÇÕES DE MISSIONÁRIOS NO MARANHÃO}

$\mathrm{E}$ mbora os itinerários dos sacerdotes Fidei Donum engajados em "causas sociais" e em mobilizações coletivas no Maranhão se prestem muito dificilmente à constituição de percursos típicos, a tentativa de situar seu estudo no conjunto mais amplo de condições sociais, institucionais e ideológicas que possibilitaram e/ou legitimaram seus engajamentos permitiu delimitar a existência de duas gerações missionárias. Três aspectos principais foram considerados: as condições de socialização institucional, o período de ingresso em território brasileiro e as características da configuração eclesiástica maranhense.

0 primeiro estrato geracional da população reunia os sacerdotes formados e ordenados em quadros institucionais ainda rígidos, entre as décadas de 1930 e 1960, mas que começaram a ser fortemente afetados pela lógica de reconquista missionária de influência da Igreja e pela efervescência apostólica que redesenhou a dialética do centro/margem do catolicismo na atmosfera pré-conciliar. Situados numa fase de desestruturação/reestruturação do espaço católico em nível mundial, esses sacerdotes foram socializados em seminários em processo de "abertura para o mundo", em concomitância com o processo de renovação dos modelos de atuação missionária da Igreja no cenário internacional (Mabille, 2001; Pelletier, 2000). Situados entre dois mundos, quase nada em suas experiências anteriores os havia preparado para o que encontrariam nos territórios missionários a que foram destinados. Assim, quando chegavam a campo, eram confrontados com circunstâncias históricas que eram muito diferentes daquelas em que haviam sido socializados e exigiam a descoberta de novas formas de agir e de perceber a si próprios. Em boa medida, suas experiências eram análogas às dos jovens voluntários que participaram da campanha do Mississipi Freedom Summer, analisados por McAdam (2012: 21-22), para os quais o evento foi experimentado sob o signo da disjunção entre história e biografia, abrindo um "período de ressocialização completa, na medida em que os percursos e as identidades se reconfigura[va]m segundo a ideia nova que faziam dos imperativos históricos".

A atuação missionária daqueles religiosos tornou-se inseparável das condições práticas de "contra-incorporação de uma cultura clerical" (Suaud, 1991: 56) por meio da qual 
se operou uma reconfiguração identitária capaz de favorecer uma adequação subjetiva às novas injunções a que eram submetidos. É precisamente nesse sentido que a configuração institucional do catolicismo e a configuração do contexto maranhense se mostram significativas. A particularidade dos anos 1950/1960 - quando se aprofundou a onda de imigração religiosa - foi que, à medida que se tinha um alargamento das esferas de atuação clerical na região, sobretudo com o direcionamento de investimentos pastorais a novas frações do laicato (camponeses, operários, moradores de periferia) portadoras de demandas religiosas inéditas, a região era atravessada pela explosão de violências e conflitos no campo e na cidade, afetando justamente aqueles segmentos. Nessa conjuntura, o papel catalisador exercido pela Igreja foi inseparável da recomposição de suas lógicas de presença territorial, dos recursos organizacionais, ideológicos e simbólicos que passou a fornecer para mobilizações nos diferentes quadros regionais. Como consequência, a inscrição de seus representantes institucionais num turbilhão de situações dramáticas e de risco, que funcionavam como efetivos modos de socialização política - de maneira mais ou menos acentuada segundo os modos que conheceram previamente - interpelava-os à ação política.

Confrontados com as insuficiências institucionais e deslocados, quase por conta própria, para regiões que não contavam com assistência religiosa regular e cujos modelos Ihes pareciam obsoletos, esses indivíduos não escapavam às solicitações de experiências de antagonismo que incitavam tanto a promoção de novas modalidades de enquadramento dentro das estruturas existentes quanto a busca de outra identidade sacerdotal. A exploração de novas formas de apostolado e de ação pastoral que seus itinerários exibem é assim inseparável dos cruzamentos entre percursos individuais, da evolução do universo religioso e das transformações do contexto sociocultural e organizacional em pauta. Em suma, ao mesmo tempo contra esses condicionantes e graças a eles, os missionários enfocados tiveram de realizar um longo e paciente trabalho sobre si para se redefinir segundo modelos pastorais inéditos e, simultaneamente, responder às indagações surgidas do meio social e institucional em que se inseriam.

A configuração eclesiástica no contexto pós-conciliar das décadas de 1970 e 1990 era distinta da anterior sob vários ângulos. Primeiramente, era caracterizada por uma maior flutuação das normas da instituição eclesial promovida e legitimada pela alta cúpula eclesiástica (Pelletier, 2002). 0 Concílio Vaticano II e, sobretudo, as conferências do episcopado latino-americano de Medellín (1968) e Puebla (1979) legitimaram diversas inovações no catolicismo latino-americano e brasileiro (CEBs, Teologia da Libertação, prioridade aos "pobres", denúncias contra a tortura) que exerciam considerável atração sobre missionários estrangeiros (Serbin, 2008; Aldighieri, 2009). Além disso, a maior parte dos missionários passou a vir de ambientes de formação seminarística com perfil mais cosmopolita e aberto. Não apenas as novas tendências teológicas, 
mas também as sociológicas, filosóficas e artístico-literárias eram mais abertamente discutidas, momento em que os futuros sacerdotes percebiam a fecundidade e a legitimidade da descoberta dos outros ou, como disse Lagroye (2006: 181), dessa espécie de "experiência concreta, dolorosa e exaltante ao mesmo tempo, de viver e de modos de pensar em contradição com aqueles que eles tinham aprendido ou continuavam a viver nas atividades de sua instituição" . " Diferentemente do que ocorreu com os missionários que chegaram ao Maranhão na configuração anterior e que não tinham como horizonte imediato a possibilidade de partida para outro país, quando a geração seguinte se formou havia diversos incentivos para viajar ao exterior (palestras, filmes) e centros dedicados especificamente à preparação dos missionários, demarcando a existência de uma verdadeira "empresa missionária".

Socializados num período de avançada renovação estrutural e pastoral que conduzia à desqualificação das formas tradicionais de exercício do sacerdócio - sem que o novo papel dessa camada média da Igreja estivesse claro (Serbin, 2008) -, os novos presbíteros sentiam-se convidados a exercer seu ministério de diversas maneiras. Destacavam-se sobretudo condições que os distanciavam da figura tradicional de um padre vinculado a uma paróquia ou que os inseriam diretamente em ações pastorais, organizações sociais, culturais, sindicais ou políticas não controladas efetivamente pela hierarquia. A própria opção pelo engajamento missionário constituía, por vezes, uma oportunidade para romper com a previsibilidade de suas carreiras em paróquias próximas à sua localidade de origem, abrindo assim novas possibilidades de radicalidade evangélica (Aldighieri, 2009), como indicam muitos itinerários. Compreende-se melhor assim o fato de que desde quando desembarcaram no distante território missionário, esses sacerdotes tenham ocupado preferencialmente posições em organismos confessionais ou ecumênicos situados nas fronteiras da instituição, de onde podiam melhor administrar a incompatibilidade sentida entre as disposições inovadoras que haviam incorporado e as possibilidades efetivas de fazê-lo a partir dos postos e das definições tradicionais do ofício.

Por outro lado, à medida que o estado do Maranhão vivia o aumento de conflitos no campo e na cidade e começavam a surgir diversas mobilizações (Carneiro, 2013; Borges, 2008; Pereira, 2011), a configuração eclesiástica demonstrava sinais de renovação. Em primeiro lugar, o próprio deslocamento dos sacerdotes já constituía indicação de maior integração da Igreja maranhense às redes internacionais de cooperação católica e às novas exigências evangélicas em curso - muito embora isso também se explicasse pelas necessidades de reprodução de uma Igreja em séria crise de recrutamento. Destaca-se igualmente a complexificação da rede organizacional em torno da Igreja - Comunidades Eclesiais de Base, criação da Comissão Pastoral da Terra, do Conselho Indigenista Missionário e da Cáritas etc. -, que não apenas erigiu uma estrutura com postos e atividades mais atrativos para as expectativas de engajamento desses 
religiosos, mas também favoreceu sua aproximação com as categorias mais politizadas do clero e do laicato atuantes na região. Esse processo de aproximação pastoral da Igreja com os grupos de leigos mais afastados de seus investimentos tradicionais pouco a pouco funcionou como estratégia eficaz de inserção, fomentando a criação de canais de sociabilidade militante e a ampliação de redes de contatos que incentivaram trânsitos e cruzamentos de categorias religiosas e políticas nos dois sentidos. Tal dado ajuda a explicar como esses clérigos passaram a integrar uma rede dentro de canais formais e informais que ampliavam as inserções e as vinculações dos religiosos com diversas esferas de atuação na região.

\section{CONSIDERAÇÕES FINAIS}

C o Brasil é hoje o segundo maior exportador de missionários católicos do mundo e tem $\checkmark$ papel de destaque no âmbito da Igreja mundial, é preciso recordar o quanto a relação com o internacional foi distinta em passado recente. Neste artigo procuramos evidenciar parte dos efeitos da circulação internacional de quadros religiosos pelo duplo ângulo da recomposição institucional e das próprias formas de exercício do papel sacerdotal. Com foco em um universo empírico considerado privilegiado para a apreensão desse tipo de processo, o expediente utilizado buscou conectar ao mesmo tempo questões e dimensões de análise via de regra tomadas em separado pelos estudos disponíveis. Como é notadamente o caso da mobilização de uma vasta estrutura internacional para o atendimento de circunscrições em situação precária no Brasil - porém em condições de acionar recursos no exterior -, a análise atentou para mudanças institucionais sofridas em diversas escalas ao longo do século XX.

0 estudo dos impactos concretos da atração e atuação de religiosos estrangeiros no Maranhão em dois momentos distintos da Igreja permitiu desvelar parte das múltiplas engrenagens de uma instituição que, sob o mesmo nome, pode significar coisas muito variadas, como lembra Jacques Lagroye (2009). E talvez um dos pontos mais reveladores levantados pela análise esteja na indicação de que, embora o Vaticano constitua a influência internacional mais importante na Igreja, esse poder centralizado teve de se defrontar constantemente, ao longo do século XX, com os desafios interpostos por dinâmicas religiosas, missionárias e leigas que, ainda que promovidas por ele próprio, escapavam-lhe largamente ao controle e chegavam a gerar situações conflituosas e até mesmo a relativização das normas institucionais e doutrinárias da Igreja Católica. É nessa perspectiva que se enquadra a tentativa de demonstração dos vínculos entre a mobilização de redes transnacionais católicas - ampliadas no pós-guerra - e o fenômeno de politização do engajamento religioso vivenciado em um componente institucional periférico como o maranhense. 
Em situação de crise de reprodução da igreja local maranhense, o apelo bem sucedido à estrutura internacional disponível significou notável ampliação de denominações, identidades religiosas e estilos pastorais em um universo cuja marca passou a ser a heterogeneidade. A expansão das denominações e das identidades envolvidas em tarefas pastorais teve como consequência a diversificação dos habitus eclesiais e, com isso, o aprofundamento do processo de diferenciação nos modos de exercício do papel religioso. Inadvertidamente, o processo de modificação na composição do clero responsável pela reprodução da Igreja no Maranhão introduziu atores com disposições distintas para perceberem as novas propostas teológicas como relevantes. E mais, também suscitou novas condições de exercício de papéis religiosos mais distanciados dos compromissos e lógicas de intervenção eclesial que caracterizavam o estado imediatamente anterior da configuração eclesiástica regional, quando havia um maior ajustamento entre a Igreja e os princípios de distribuição do poder em uma sociedade fracamente diversificada e rural como a maranhense.

\section{Notas}

1 Circunscrição eclesiástica é cada uma das unidades autônomas em que a Igreja Católica está subdividida para efeitos pastorais e administrativos. A circunscrição eclesiástica típica é a diocese. Dioceses próximas entre si agrupam-se em Províncias Eclesiásticas, sem perder a própria autonomia, sob a presidência de uma delas, designada Arquidiocese. As Prelazias se diferenciam das dioceses somente por serem circunscrições ainda em processo de consolidação, já que se localizam geralmente em áreas remotas e de poucos recursos.

2 Para o estudo desse processo em outro contexto, ver Seidl (2012).

3 Sobre as mudanças no processo de formação seminarística pós-conciliar, consultar Serbin (2008) e Seidl (2003, esp. 238-280).

4 Uma análise das relações entre tipo de formação religiosa, contexto político e seus efeitos sobre as concepções do papel religioso nas carreiras de bispos e padres intelectuais no período pós-conciliar pode ser consultada em Seidl (2009).

\section{REFERÊNCIAS BIBLIOGRÁFICAS}

ALDIGHIERI, Mario. L'esperienza dei preti italiani ed europei "fidei donum" in America Latina. Rivista Credereoggi. Teologia in America Latina, $n^{0}$ 171, (3), 2009.

ALVES, Marcio Moreira. A Igreja e a política no Brasil. São Paulo: Brasiliense, 1979.

AZZI, Riolando. Presença da Igreja na sociedade brasileira e formação das dioceses no período republicano. In: SOUZA, Rogério Luiz de; OTTO, Clarícia (orgs.). Faces do catolicismo. Florianópolis: Insular, 2008.

BEOZZO, José O. Padres conciliares brasileiros no Vaticano Il: participação e prosopografia 1959-1965. Tese (Doutorado em História). Faculdade de Filosofia, Letras e Ciências Humanas, USP, 2001. 
BETRAMI, Fr. Rogério. Que coisa difícil e bonita falar sobre a nossa presença capuchinha. In: CONVENTO do Carmo. São Luís do Maranhão. Saíram para semear... E já faz cem anos que a semente caiu em terra boa... São Luís: Velar, 1993.

BORGES, Arleth S. PT Maranhão 1980-1992: origens, organização e governos municipais. São Luís: EDUFMA, 2008. BRUNEAU, Thomas C. O catolicismo brasileiro em época de transição. São Paulo: Loyola, 1974. - Religião e politização no Brasil. São Paulo: Loyola, 1979.

CARNEIRO, Marcelo D. S. Terra, trabalho e poder: conflitos e lutas sociais no Maranhão contemporâneo. São Paulo: Anablume, 2013.

CERIS - Centro de Estatística Religiosa e Investigações Sociais. Anuários Católicos Do Brasil. Disponível em: http://www.cps.fgv.br/cps/religiao. Acesso em 21 de março de 2013.

CERIS. Dinâmica populacional e a Igreja Católica no Brasil: 1960-2000. Rio de Janeiro, ano 2, n. 3, out. 2002. CHAOUCH, Malik T. La théologie de la libération en Amérique latine. Archives de Sciences Sociales des Religions, 138, 2007.

CUTER, Frei Franco. Esta é a história dos nossos Cem anos quando foram criados... In: CONVENTO do Carmo. São Luís do Maranhão. Saíram para semear... E já faz cem anos que a semente caiu em terra boa... São Luís: Velar, 1993.

DALABRIDA, Norberto. A fabricação escolar das elites: o Ginásio Catarinense na Primeira República. Florianópolis: Cidade Futura, 2001.

DE ROUX, Rodolfo. La romanización de la Iglesia católica en América Latina: una estratégia de larga duración. Pro-Posições, Campinas, v. 25, n. 1, 2014.

DELLA CAVA, Ralph. Religiões transnacionais: Igreja Católica Romana no Brasil e a Igreja Ortodoxa da Rússia. Civitas, Porto Alegre, v. 3, n. 1. 2003.

ESTATÍSTICA do Culto Católico Romano. Serviço de estatística demográfica; moral; política. Províncias eclesiásticas do Brasil, 1950.

ESTATÍSTICA do Culto Católico Romano (IBGE). Série histórica de 1936 a 1983. Disponivel em: http://seculoxx.ibge.gov.br/populacionais-sociais-politicas-e-culturais/busca-por-palavra-chave/associativismo/606-culto-catolico. Acesso em 19 de março de 2013.

IFFLY, Catherine. Transformar a metrópole: Igreja católica, territórios e mobilizações sociais no Brasil, 19702000. São Paulo: UNESP, 2010.

LAGROYE, Jacques. La vérité dans l'Église catholique. Contestations e restauration d'un régime d'autorité. Paris: Belin, 2006.

Appartenir à une institution: catholiques en France aujourd'hui. Paris: Economica 2009.

LEONARDI, Paula. Puríssimo coração: um colégio de elite em Rio Claro. Dissertação (Mestrado em Educação). Unicamp, Campinas, 2002.

MABILLE, François. Approches de l'internationalisme catholique. Paris: L'Harmattan, 2001.

MACHADO, Jorge L. F. Ação política, missão pastoral e instâncias de inserção: engajamento de clérigos no Maranhão (1970-1980). Dissertação (Mestrado em Ciências Sociais). Universidade Federal do Maranhão, 2012. 
MAINWARING, Scott. Igreja Católica e política no Brasil. São Paulo: Brasiliense, 2004.

McADAM, Doug. Freedom Summer. Luttes pour les droits civiques. Mississippi, 1964. Paris: Agone. 2012.

MEIRELLES, Mário M. História da Arquidiocese de São Luís do Maranhão. São Luís, Universidade do Maranhão/SIOGE, 1977.

MENDEZ, Carlos A. P. Pontifícia Comissão para a América Latina, 50 anos (1958-2008). Monografia Histórica. 2008.

MICELI, Sérgio. A elite eclesiástica brasileira. Rio de Janeiro: Bertrand Brasil, 1988.

NERIS, Wheriston Silva. A elite eclesiástica no bispado do Maranhão. São Luís/Jundiaí: Edufma/Paco Editorial, $2014 a$.

Igreja e missão: religiosos e ação política no Brasil. Tese (Doutorado em Sociologia). Universidade Federal de Sergipe, São Cristóvão, 2014b.

; SEIDL, Ernesto. Circulação internacional, politização e redefinições do papel religioso. Revista Brasileira de História da Educação, 2014 (no prelo).

OLIVEIRA, Pedro. A. R. de. 0 papel do padre - 1968-2004. In: MEDEIROS, Kátia M. C; FERNANDES, Sílvia R. A. O padre no Brasil: interpelações, dilemas e esperanças. São Paulo: Loyola, 2005.

PACHECO, D. Felipe Condurú. História eclesiástica do Maranhão. São Luís: Departamento de Cultura do Estado, 1969.

PELLETIER, Denis. De la mision au tiers-mondisme: crise ou mutation d'un modèle d'engagement catholique. Le Mouvement Social, oct.-dec., n. ${ }^{\circ}$ 177, 1996.

Le militantisme chrétien à l'épreuve de I'idée missionaire. In: BRECHON, Pierre; DURIEZ, Bruno; ION, Jacques. Religion et action dans l'espace publique. Paris: L'Harmattan. 2000.

. La crise catholique. Religion, societé, politique en France (1965-1978). Paris: Payot. 2002.

PEREIRA, Jesus. M. Engajamento militante e a "luta pela moradia em São Luís" entre as décadas de 1970 e 1980. Dissertação (Mestrado em Ciências Sociais). Universidade Federal do Maranhão, São Luís, 2011.

PREZIA, Benedito (org.). Caminhando na luta e na esperança: retrospectiva dos últimos 60 anos da Pastoral Indigenista e dos 30 anos do CIMI. São Paulo: Loyola, 2003.

PRUDHOMME, C. Le modèle missionnaire: stratégies et débats. In: DOUAIRE-MARSAUDON, Françoise et al. Missionnaires chrétiens. Autrement Mémoires/Histoire, 2008.

RAISON DU CLEZIOU, Yann. De la contemplation à la contestation: socio-histoire de la politisation des dominicains de la Province de France (1954-1969). IXème Congrès de l'Association Française de Science Politique. Toulouse, 2007.

REVEL, Jacques. Jogos de escala: a experiência da microanálise. Rio de Janeiro: FGV Editora, 1998.

SCHWARTZMAN, Simon. A política da Igreja e a educação: o sentido de um pacto. Religião e Sociedade, 13/1, 1986.

SEIDL, Ernesto. A elite eclesiástica no Rio Grande do Sul. Tese (Doutorado em Ciência Política). Universidade Federal do Rio Grande do Sul, Porto Alegre, 2003.

. Lógicas cruzadas: carreiras religiosas e política. Revista Pós Ciências Sociais, v. 6, 2009.

Igreja e construção nacional no Brasil e na Argentina. In: HEINZ, Flávio M. (org.). Poder, instituições e

elites: 7 ensaios de comparação e história. São Leopoldo: Oikos, 2012. 
Circulação internacional de religiosos, formação de quadros católicos e condições de intervenção política. Projeto de Pesquisa, CNPq, mimeo, 2014.

; NERIS, Wheriston S. 0 episcopado brasileiro e o espaço do poder: uma cultura eclesiástica em mutação. Revista Pós Ciências Sociais, v. 8, 2011.

SERBIN, Kenneth. P. Padres, celibato e conflito social: uma história da Igreja católica no Brasil. São Paulo: Companhia das Letras, 2008.

SUAUD, Charles. As lutas religiosas do ponto de vista de uma sociologia da incorporação. 0 corpo sacerdotal (católico) entre doutrina e inovação. Revista da Faculdade de Letras/Sociologia, Universidade do Porto, vol. 1, 1991.

WERNET, Augustin. Crise e definhamento das tradicionais ordens monásticas brasileiras durante o século XIX. Revista do Instituto de Estudos Brasileiro, São Paulo, n. 42, 1997.

\section{JORNAIS CONSULTADOS}

O Estado de S. Paulo (1973-1980)

Jornal do Maranhão (1958-1968)

\section{Sites CONSULTADOS}

http://www.catholic-hierarchy.org/ 